\title{
Could the reproductive system explain the stability and long-term persistence in a natural hybrid zone of Petunia (Solanaceae)?
}

\author{
Marcelo C. Teixeira ${ }^{1,2}$ (D), Caroline Turchetto ${ }^{1}$ (D), Carolina K. Schnitzler ${ }^{1}$ (D), Sidia M. Callegari-Jacques ${ }^{3}$ (D) \\ and Loreta B. Freitas ${ }^{1,2 *}$ (1)
}

Received: December 18, 2020

Accepted: June 19, 2021

\begin{abstract}
The long-term success of populations is dependent on individual reproductive success, and in general, increased population size and genetic diversity contribute to population maintenance, reducing the risk of local extinction. Interspecific hybridization has consequences that can vary according to the hybrids' fate, which can be strongly influenced by the reproductive capacity of hybrids and canonical individuals from the contact zone. We examined the reproductive biology and morphology of two closely related Petunia (Solanaceae) species and their interspecific hybrids from Serra do Sudeste, Southern Brazil, and we measured their reproductive success under controlled conditions based on seed production and germination from five pollination treatments. We found differences in selfcompatibility degree among individuals, lineages, and pollination treatments based on high total seed production (> 204,000 seeds) and germination (630 seedlings evaluated). No correlation was observed between corolla colour and reproductive success or between floral morphological traits and compatibility. High self-compatibility and inter-lineage compatibility can explain the hybrid populations' maintenance and origin, favouring the two analysed species' introgression.
\end{abstract}

Keywords: reproductive success, interspecific hybridization, mating system, germinability, Petunia

\section{Introduction}

The long-term success of populations is dependent on individual reproductive success, and in general, increased population size and genetic diversity contribute to population maintenance, reducing the risk of local extinction (Wubs et al. 2010). Mainly for pioneer plants that are colonising new environments, self-fertilization and inbreeding may result in a reduction in fitness but, on the other hand, can ensure successive generations (Keller \& Waller 2002).
Interspecific hybridization is the basis of angiosperm diversification (Soltis \& Soltis 2009), and its consequences can vary in the function of the hybrids' fate (Ellstrand et al. 2013; Todesco et al. 2016). Closely related species that occur in sympatry may experience reciprocal pollen flow that may or may not lead to hybrid descendants' formation. In turn, hybrids may show morphological differences and shifts in the mating system or pollinator interaction compared with their parents (Hopkins 2013), and their viability and reproductive potential would determine the success of these novel lineages (Vilà et al. 2000). Potential outcomes

1 Laboratório de Evolução Molecular, Departamento de Genética, Universidade Federal do Rio Grande do Sul, 90509-900, Porto Alegre, RS, Brazil 2 Programa de Pós-Graduação em Botânica, Universidade Federal do Rio Grande do Sul, 90509-900, Porto Alegre, RS, Brazil

3 Departamento de Estatística, Universidade Federal do Rio Grande do Sul, 90509-900, Porto Alegre, RS, Brazil

* Corresponding author: loreta.freitas@ufrgs.br 
for hybrids can be heterosis, which is established when hybrids show enhanced growth or function, or outbreeding depression when hybrids have lower fitness than parents (Oakley et al. 2015). Hybridization can lead to severe floral morphology changes, which may cause shifts in pollinator attractive traits (Teixeira et al. 2020) with a priori unpredictable impact on population or species' fate. Changes in pigmentation, scent emission, ultraviolet light response, nectar production or composition, and floral morphology, in general, are associated with evolutionary shifts leading to speciation (Esfeld et al. 2018; Rodrigues et al. 2018b), and all these traits can be affected by interspecific hybridization.

Variation in herkogamy or operative distance (i.e., the distance among rewards and anthers and stigma) and other floral traits (e.g., corolla shape and size, corolla colour and aroma) can have different effects on the pollinator's visitation, mating success, and fitness gain dependently on the mating systems (Karron et al. 2012). Differences in fruit or seed quantities and seedling viability have been observed as mating systems dependent, and evolutionary issues on the advantage of selfing versus outcrossing mating strategies to establish or maintain a population have been debated for a long time (Cheptou 2019). Several studies in plants have used fruit formation, seed quantity, and seedling survival as parameters to estimate the population or species fitness (Bigio et al. 2017), thus assessing the stability and potential persistence of a population or species.

The genus Petunia (Solanaceae) encompasses species with high floral morphology diversity (Knapp 2010) that are mainly associated with different pollination syndromes (Fregonezi et al. 2013). Despite the lack of intrinsic barriers against hybridization, at least under controlled conditions (Dell' Olivo \& Kuhlemeier 2013), natural hybrids are scarcely found (Lorenz-Lemke et al. 2006). Petunia exserta and $P$. axillaris exhibit perceived contrasting red and white corolla colours by the human eyes, respectively, and individuals with intermediate corolla colour are found in a sympatric zone between them. The intermediate-coloured individuals were considered hybrids based on genetic data (Lorenz-Lemke et al. 2006; Segatto et al. 2014; Turchetto et al. 2015b; 2019a; b; Teixeira et al. 2019) and they also display different corolla shape compared to the species, not necessarily intermediate between the canonical morphologies of the two species (Teixeira et al. 2020). As the canonical type, we considered plants displaying all traits according to the species description, respectively (Stehmann et al. 2009). To date, $P$. axillaris has an erect habit, salverform white corolla, yellow pollen, and inflexed pedicel in fruit stage, with scented flowers at dusk; P. exserta shows red (red-orange) corolla and distinct exerted stamens and stigma, and share with $P$. axillaris the erect habit, salverform corolla, yellow pollen, and inflexed stalk. Moreover, $P$. axillaris is only found in open and sunny environments, whereas $P$. exserta individuals grow in shady places (Lorenz-Lemke et al. 2006).
In this study, we examined the reproductive biology and morphology of floral traits of the P. exserta, P. axillaris, and interspecific hybrids from the contact zone between these species in southern Brazil under controlled conditions. Our goal was to evaluate differences in reproductive success among species and their hybrids to determine whether the corolla colour classes, which correspond to the morphological description previously observed for canonical and hybrid individuals (Teixeira et al. 2020), are interfertile and self-compatible. To accomplish this goal, we assessed differences in fruit production, seed quantity (number of seeds per fruit), and seed germination (number of seedlings that reached true-leaves stage) derived from controlled pollination experiments in a greenhouse; we also evaluated the association of these results with the corolla tube length and the distance between the stigma and dorsal anthers. We are motivated by the fact that these hybrid populations are observed for a long time with no changes in size or genetic polymorphism (Schnitzler et al. 2020), even with most individuals displaying characteristics that are not related to the canonical species (Teixeira et al. 2020) and, therefore, not included in parental floral syndromes.

\section{Materials and methods}

\section{Study system}

Petunia exserta Stehmann and P. axillaris (Lam.) Britton Sterns \& Poggenb are herbaceous and annual species that grow in South America's grasslands (Stehmann et al. 2009; Fregonezi et al. 2013). The red-flowered P. exserta is endemic to a locality formed by sandstone towers with $200 \mathrm{~m}$ to $500 \mathrm{~m}$ in elevation, known as Guaritas in Serra do Sudeste, Southern Brazil (Stehmann et al. 2009). Petunia axillaris has a white corolla colour and is widespread throughout the Pampas and Chaco ecoregions and in adjacent mountains in the Andean areas (Turchetto et al. 2014b); three subspecies are proposed to P. axillaris based mainly on floral morphology and distribution areas (Ando 1996; Kokubun et al. 2006). These subspecies constitute different evolutionary lineages based on molecular and ecological data (Turchetto et al. 2014a) and P. axillaris subsp. axillaris (hereafter referred to as P. axillaris) only grows in the Pampas' open fields in southern Brazil, Uruguay, and Argentina. The geographic distribution of this subspecies overlaps with the range of $P$. exserta in Serra do Sudeste. Although P. axillaris and $P$. exserta grow in this same location, these two taxa occupy different microhabitats. Petunia exserta is found inside small cavities in the towers (caves or shelters), entirely protected against direct sunlight and rain, on shallow soil (LorenzLemke et al. 2006; Segatto et al. 2014). Petunia axillaris grows in the open areas of grasslands on towers' top or faces (Turchetto et al. 2014a; 2015a). These species share some morphological traits, such as a hypocrateriform corolla, 
yellow pollen, and capsule fruits with hundreds of seeds. On the other hand, they show specific floral traits related to the main effective pollinators for each species, as they are responsible for attracting the pollinator and allowing pollen removal and deposition, indicating the respective floral syndromes (Etcheverry \& Alemán 2005). Whereas P. exserta is a hummingbird-pollinated species (Lorenz-Lemke et al. 2006) displaying bright red petals, exserted anthers, and non-fragrant and UV-reflective corollas, P. axillaris is a hawk moth-pollinated plant (Galetto \& Bernardello 1993; Ando et al. 2001; Venail et al. 2010) with white and smelling corollas that absorb UV light. Pollination experiments indicated that P. exserta is a self-compatible (SC) species (Stehmann et al. 2009), and P. axillaris was considered a self-incompatible (SI) species (Ando et al. 1998). A study based on a pollen flow conducted in the Guaritas area (Turchetto et al. 2015a) revealed that $P$. axillaris has a mixed mating system, at least in populations from this region.

Two sites in the Guaritas region are particularly intriguing because, during several years, individuals of $P$. axillaris and $P$. exserta were found close to individuals displaying flowers with different shades of intermediate colours (Fig. 1). The individuals' floral morphology in those sites ranges from canonical P. exserta to canonical P. axillaris, at extremes, with five intermediate corolla colours between them (Teixeira et al. 2020). As commonly observed with other Petunia species, these sites comprise small patches with few individuals closely distributed. The few works conducted to evaluate reproductive compatibility in Petunia species revealed that even the self-compatible species are dependent on a pollen vector (Ando et al. 1998; Turchetto et al. 2015a; Rodrigues et al. 2018a) because there is no autonomous self-pollination neither fruit production by apomixis.

\section{Plant sources}

We collected all mature fruits found in the two sites in

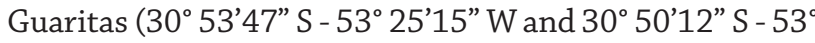
$\left.30^{\prime} 15^{\prime \prime} \mathrm{W}\right)$ where canonicals and intermediate coloured individuals are found (Fig. 1). We pooled the seeds together based on the mother plant corolla colour (identified as classes A, B, C, D, and E with intermediate corolla colour, based on a Red-Green-Blue (RGB) colour chart according to Teixeira et al. (2020), P. axillaris, and P. exserta). We used an RBG-based classification to identify the hybrid morphologies

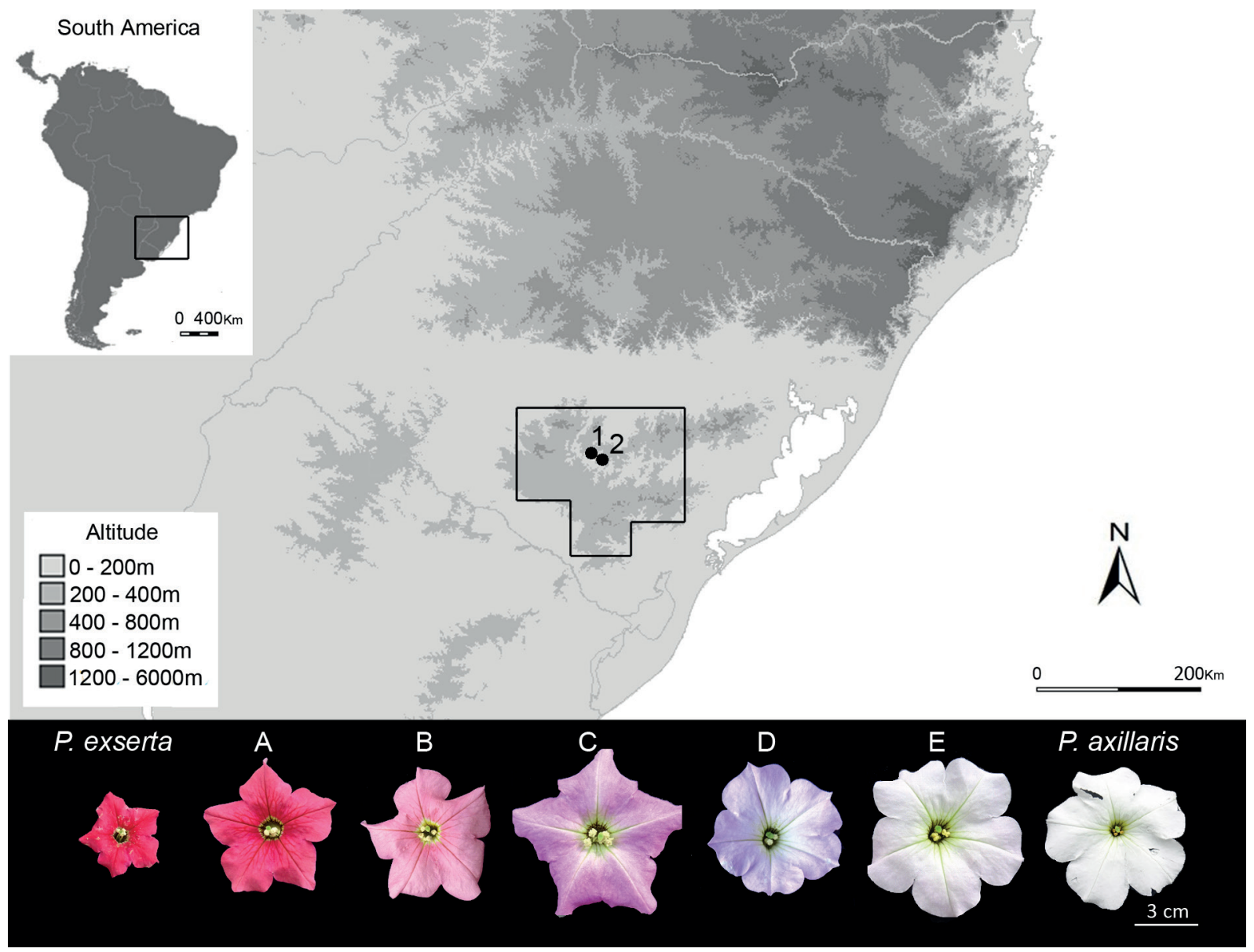

Figure 1. The original collection sites' geographical location in nature and visible colour of flowers that are found in the contact zone between $P$. exserta (left) and P. axillaris (right). Intermediate coloured individuals were classified into five classes according to an RGB (red-green-blue) chart as A to E (center) for human eye perception. 
because it corresponds to a set of shape, measures, and genetic traits easily discriminated by humans' observation, despite that it is not necessarily the same for pollinators. Vouchers for these sites were deposited at ICN herbarium (Universidade Federal do Rio Grande do Sul, Porto Alegre, Brazil): P. exserta-ICN185146; P. axillaris-ICN185145; Hybrid A-ICN 200858; Hybrid B-ICN 200859; Hybrid C-ICN 200860; Hybrid D-ICN 200861; and Hybrid EICN 200862. One seed per pot was sown in 5-mL plastic pots, filled with commercial soil, and maintained in a growth chamber at $22^{\circ} \mathrm{C}$ in a 12 -h light: 12 -h dark cycle. Before the germination process, the seeds were pre-treated with gibberellic acid: dimethyl sulfoxide solution, according to Rodrigues et al. (2018a). We transferred the 60-day-old seedlings to a greenhouse in 0.6 -L plastic pots filled with commercial soil (70\%): vermiculite $(15 \%)$ : sterile sand $(15 \%)$, maintained siblings under uniform humidity, natural luminosity, and an air temperature of $26 \pm 5^{\circ} \mathrm{C}$, and cultivated these plants until blooming. A commercial nutritive solution ( $4 \%$ nitrogen:14\% phosphorous:8\% potassium) was added to the soil every 15 days. The germination and cultivation conditions are successfully employed to obtain wild Petunia plants in greenhouse experiments (Turchetto et al. 2015a; Rodrigues et al. 2018b; Teixeira et al. 2020). We selected a set of 21 plants by the visual assessment of the corolla colour encompassing the five intermediate colour classes, $P$. exserta, and P. axillaris (Fig. 1), three plants per colour class.

\section{Floral traits}

We measured two floral characteristics, corolla tube length and distance between the stigma and dorsal anthers, to evaluate whether they could be associated with different pollination treatment or plant visible colour phenotypes in the greenhouse. Based on previous experimental tests in a greenhouse and personal observations in the field that indicate low variability among individuals in each colour class, we measured three flowers on the first day-open stage per plant (63 flowers in total) and used the mean values as the colour classes measure to evaluate: (1) the variation in measures of hybrid plants compared with those observed in canonical individuals of each species; (2) the success in fruit production from spontaneous selfpollination related to the difference between the stigma and the dorsal anthers; and (3) the correlation between reproductive success (fruit production) and tube length. We employed such evaluations to verify whether differences in flower tube length and distance between stigma and anthers favor spontaneous selfing, ensuring hybrid in the absence of pollen vectors.

\section{Pollination experiments}

We performed manual crosses under controlled conditions (pollination treatments) for canonical $P$. exserta and P. axillaris individuals and each intermediate corolla colour class in a greenhouse. Hand pollination was conducted by removing one anther of a donor flower with a metallic pin and placing this anther on the recipient flower's stigma. All hand pollinations were performed in the same floral phase (newly opened flowers), and, to prevent accidental selfing, we emasculated the recipient buds just before anthesis. We conducted five pollination treatments: (1) spontaneous self-pollination-intact buds were bagged (SS); (2) hand self-pollination-manually fertilised with self-pollen (HS); (3) autonomous apomixis - the anthers were removed, and the buds were bagged (APo); (4) hand geitonogamy - the flowers were manually fertilised with pollen from another flower of the same individual (GEi); and (5) hand cross-pollination - the flowers were manually pollinated with pollen from other plants from the same or other colour classes. We analysed three plants per colour class in each experiment and performed all bidirectional crosses as each colour class provided to and received pollen from each other phenotype (seven colour classes). We used only three plants because the wild Petunia populations usually encompassed just a few individuals, especially in the contact zone between $P$. axillaris and P. exserta (Schnitzler et al. 2020). Moreover, each fruit produces hundreds of small seeds, which display high viability (Rodrigues et al. 2018a; also see Results section). All these facts ensure population survival across generations (Rodrigues et al. 2019). In total, we analysed 231 flowers of 21 plants. Fruit formation was recorded, and seed quantity was estimated through the seed mass for 100 seeds per fruit evaluated in precision balance in grams. Green fruits were bagged, and we collected all seeds per mature fruit per pollination treatment in standard plastic tubes. The total seed content was then weighed, and the total number of seeds was estimated proportionally to the mass of 100 counted seeds per fruit.

\section{Germinability}

To evaluate seeds' viability from the pollination treatment, we performed a germinability test using 30 randomly selected seeds per individual in each colour class per pollination treatment. We used the same previously described pre-treatment and germination protocols. We followed the seeds for 21 days and counted how many germinated. In general, Petunia mature seeds from nature spend five days to germinate, and seedlings have the first true leaves expanded on the $21^{\text {st }}$ day.

\section{Statistical analyses}

We compared phenotypes along pollination treatments for the production and germinability of seeds based on the total of seeds or seedlings obtained in each colour class/ pollination treatment combination using a chi-square test for homogeneity and residuals. We considered hand self-pollination, hand geitonogamy, and crosses between individuals of the same colour class as intra-class crossings; crosses between hybrids of different colour classes as interclass crossings; crosses between hybrids and canonical 
individuals as backcrosses with P. exserta and P. axillaris, respectively; and crosses between $P$. exserta and $P$. axillaris as hybridization. We conducted comparisons among crosses based on the number of produced seeds and seedlings. To cope with multiple testing issues, we used a significance level of 0.0001 (Bonferroni's correction) in the analyses of Chi-square residuals. For all other tests, the result was considered statistically significant if $p<0.05$. We used a Kruskal-Wallis test to compare the two morphological traits among colour classes, whereas Pearson's coefficient measured the correlation between these two traits and seed quantity or germinability. The analyses were performed using PASW Statistics (SPSS) for Windows v. 18.0 (IBM Corp., Armonk, USA).

\section{Results}

\section{Floral trait variation}

The tube length was not significantly different among colour classes and species (Kruskal-Wallis test, $H=14.29$; $p=0.270 ;$ Tab. 1). Although it was not possible to conduct pairwise statistical comparisons between colour classes due to the small number of flowers per colour class or species, in the sampled flowers of classes $C$ and $E$, we observed the longest corolla tubes on average compared with those of the other five classes. The shortest tubes were observed in $P$. exserta flowers, whereas flowers of classes A, B, and D showed intermediate tube lengths. Concerning distance between the stigma and dorsal anthers, the highest and lowest individual values were observed in P. exserta individuals, and only two individuals displayed stigmata positioned below the anthers (Tab. 1). We did not find significant differences in herkogamy values among the colour classes (Kruskal-Wallis test, $H=6.09 ; p=0.413$ ).

\section{Crossing experiments: fruit and seed production}

In general, all the pollination treatments were successful considering all colour classes, with high fruit production. No fruits were produced by apomixis, regardless of colour class or plant individual fruits, independently of colour class or individual. Most plants (14/21) in spontaneous self -pollination treatment did not produce fruits, and only one individual that display the stigma positioned below the anthers produced fruit by SS. Most plants (19 from 21) in hand geitonogamy pollination treatment produced fruits. All fruits produced seeds, but the number of seeds varied among pollination treatments and colour classes (Tab. S1 in supplementary material). We observed a statistically significant association between colour classes and pollination treatments (Chi-squared test $p<0.001$ ) for the total number of produced seeds from three random flowers of each pollination treatment, but no clear pattern could be discerned in this association.
Table 1. Floral traits measurements ( $\mathrm{mm}$ ) per plant and corolla colour class. Each value corresponds to the mean of three flowers per individual.

\begin{tabular}{|c|c|c|c|c|c|}
\hline \multirow{2}{*}{$\begin{array}{l}\text { Colour } \\
\text { class }\end{array}$} & \multirow{2}{*}{$\begin{array}{l}\text { Plant } \\
\text { ID }\end{array}$} & \multicolumn{2}{|c|}{ Corolla tube length } & \multicolumn{2}{|c|}{$\begin{array}{l}\text { Distance between stigma } \\
\text { and dorsal anthers }\end{array}$} \\
\hline & & $\begin{array}{l}\text { Individual } \\
\text { values }\end{array}$ & $\begin{array}{l}\text { Class } \\
\text { mean }\end{array}$ & Individual values & $\begin{array}{l}\text { Class } \\
\text { mean }\end{array}$ \\
\hline \multirow{3}{*}{$\begin{array}{l}\text { Red (RGB } \\
\text { 240:33:76) }\end{array}$} & Ex1 & 37.69 & \multirow{3}{*}{35.92} & 1.88 & \multirow{3}{*}{1.62} \\
\hline & Ex2 & 35.32 & & 4.48 & \\
\hline & Ex3 & 34.75 & & -1.51 & \\
\hline \multirow{3}{*}{$\begin{array}{c}\text { A (RGB } \\
\text { 251:94:76) }\end{array}$} & A1 & 44.77 & \multirow{3}{*}{46.39} & 1.76 & \multirow{3}{*}{0.62} \\
\hline & A2 & 47.23 & & 0.66 & \\
\hline & A3 & 47.18 & & -0.55 & \\
\hline \multirow{3}{*}{$\begin{array}{c}\text { B (RGB } \\
(225: 147: 188)\end{array}$} & B1 & 49.46 & \multirow{3}{*}{46.17} & 2.04 & \multirow{3}{*}{1.43} \\
\hline & B2 & 47.23 & & 0.74 & \\
\hline & B3 & 41.83 & & 1.50 & \\
\hline \multirow{3}{*}{$\begin{array}{c}\text { C (RGB } \\
243: 183: 248)\end{array}$} & $\mathrm{C} 1$ & 47.58 & \multirow{3}{*}{49.67} & 0.07 & \multirow{3}{*}{0.32} \\
\hline & $\mathrm{C} 2$ & 49.48 & & 0.88 & \\
\hline & C3 & 51.94 & & 0.02 & \\
\hline \multirow{3}{*}{$\begin{array}{c}\text { D (RGB } \\
\text { 243:214:252) }\end{array}$} & D1 & 45.34 & \multirow{3}{*}{46.38} & 3.78 & \multirow{3}{*}{2.17} \\
\hline & D2 & 48.45 & & 1.90 & \\
\hline & D3 & 45.36 & & 0.83 & \\
\hline \multirow{3}{*}{$\begin{array}{c}\text { E (RGB } \\
\text { 238:233:243) }\end{array}$} & E1 & 50.69 & \multirow{3}{*}{51.86} & 1.06 & \multirow{3}{*}{0.63} \\
\hline & E2 & 53.48 & & 1.38 & \\
\hline & E3 & 51.41 & & 2.27 & \\
\hline \multirow{3}{*}{$\begin{array}{l}\text { White (RGB } \\
\text { 243:243:246) }\end{array}$} & $\mathrm{Ax} 1$ & 50.75 & \multirow{3}{*}{47.97} & 2.71 & \multirow{3}{*}{1.91} \\
\hline & $\mathrm{Ax} 2$ & 46.27 & & 1.62 & \\
\hline & Ax3 & 46.89 & & 1.40 & \\
\hline
\end{tabular}

Red:Green:Blue chart is according to Teixeira et al. (2020) and follows Figure 1; A to E - intermediate colour classes; Ex - P. exserta (red) colour class; Ax - P. axillaris (white) colour class; plant ID 1 to 3 - number of individuals per class.

Concerning the intermediate coloured individuals under different pollination treatment (Fig. 2A; Tab. S2 in supplementary material), hybrid mothers produced a higher number of seeds when mother plant and pollen donor were both hybrids (average contribution of pollination treatments intra-class $=32 \%$ and interclass $=48 \%$ of all produced seeds) and backcrosses contributing with smaller amounts. For Class A mother plants, the seed production decreased in intra-class crossings ( $21 \%$ of its production) compared to other intra-class crossings colour classes (34\% - 37\%). On the other hand, while for Class B mother plants the intra-class: interclass crossings odds in seed production ranged from $34 \%$ to $53 \%$, to Classes C, D, and E mothers, the contrast between intra-class and interclass crossings was differently balanced (37\%:45\%; 36\%:46\%; and 34\%:44\%, respectively).

Backcrosses were less productive than intra-class and interclass crossings when the mother plant was a hybrid (Fig. 2A; Tab. S2 in supplementary material). On average, the percentage of seeds produced was $12 \%$ considering backcrosses with P. exserta and about half of this (7\%) for backcrosses with P. axillaris. Again, this pattern varied according to the hybrid mother plant colour class. In Classes A and D, backcrosses with P. exserta produced two percent points more seeds than the average ( $14 \%$ versus $12 \%$, 

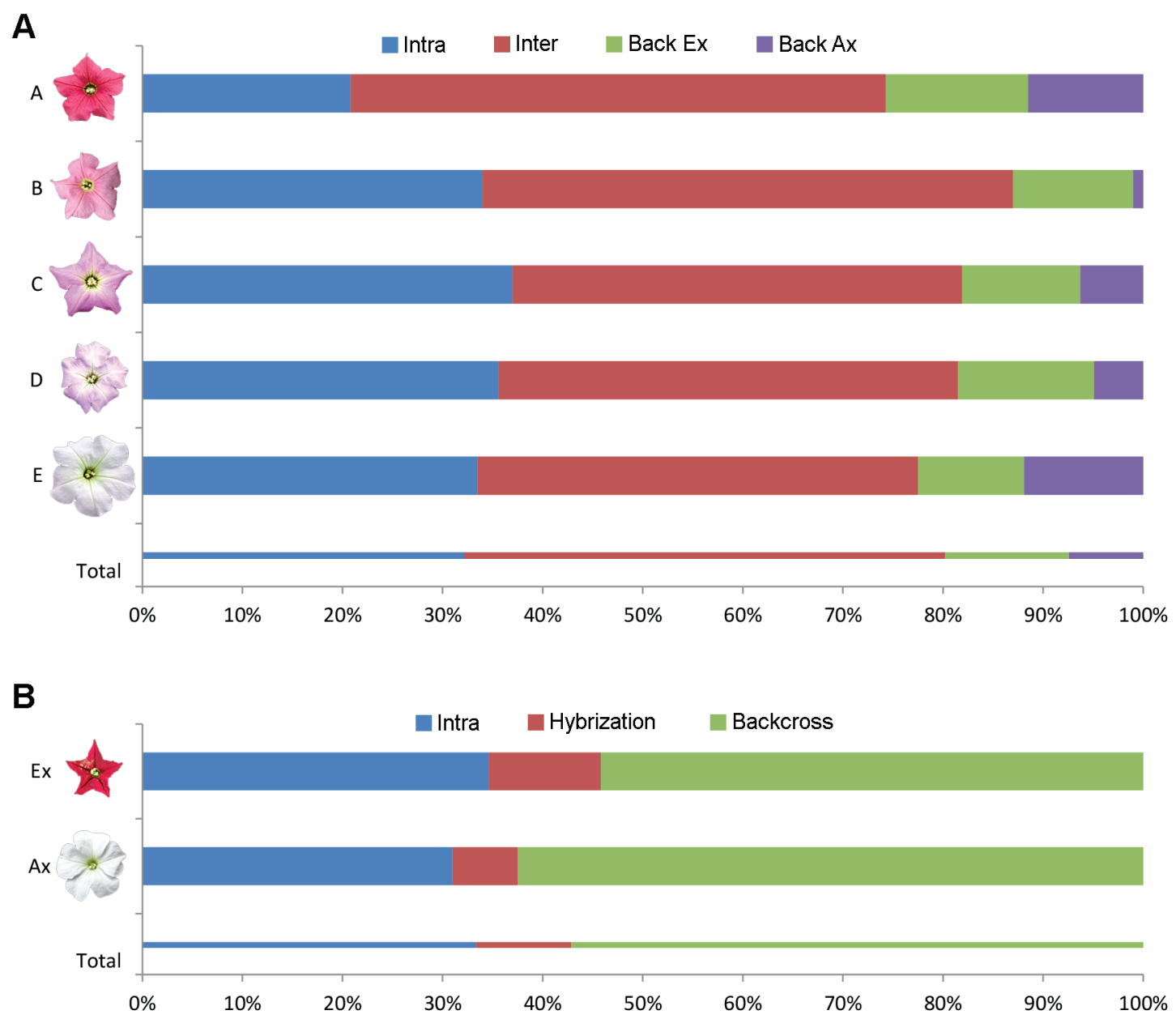

Figure 2. Schematic representation for each pollination treatment contribution on the seed production as estimated through Pearson's chi-square and considering intermediate coloured $(\mathbf{A})$ and canonical (B) individuals. For individual and significance values, see Tables S2 and S3 in supplementary material.

respectively), whereas other colour classes produced around the average. The proportion of seed production of Classes $\mathrm{A}$ and $\mathrm{E}$ mothers in backcrosses with $P$. axillaris was much higher $(12 \%)$ than the average $(7 \%)$, whereas mothers from Classes C, D, and E produced seeds below the average.

The general summary of the results (Fig. 2A; Tab. S2 in supplementary material) revealed that Class A mother plants seem to produce more seeds than the average for all pollination treatments if pollen comes from interclass crossings or any kind of backcrosses (Adj. Res. = 10.9 to 30.4). The Class B mother plants were more effective in intra-class and interclass crossings (Adj. Res. $=7.1$ and 17.7), whereas Class $C$ individuals generated more seeds from intra-class crossings (Adj. Res. $=20.9$ ). Concerning the Class D mothers, intra-class and backcrosses with $P$. exserta were the crosses that yielded more seeds. Finally, Class E flowers were especially productive in backcrosses with P. axillaris.

Examining seed production of crosses where the ovule donors were plants of the two Petunia species (Fig. 2B;
Tab. S3 in supplementary material), the most productive pollination treatment was backcross (P. exserta with $54 \%$ of all produced seeds and P. axillaris with $63 \%$ ). Hybridization between these Petunia species was the least effective pollination treatment, contributing with only $9.5 \%$, on the average, of the total seed production of these plants.

\section{Crossing experiments: seed germination}

Seed germination (Tab. S4 in supplementary material) was low (<50\%) on average, except for P. axillaris that had more than $75 \%$ of sown seeds reaching the developmental stage of true leaves. Concerning hybrid plants (Fig. 3A; Tab. S5 in supplementary material), the pollination treatments impacted seed germination only for mother plants from Classes D and E. A lower than the average percentage of viable seedlings was observed in intra-class for Class $\mathrm{D}$ mother plants ( $19 \%$ versus $32 \%$ ) and in interclass for Class E plants ( $22 \%$ versus $33 \%$ ). In contrast, intra-class crossings were responsible for higher germination for Class $E$ individuals ( $42 \%$ versus $32 \%$ ). 
Comparing the species (Fig. 3B; Tab. S6 in supplementary material), P. exserta mother plants produced more viable seedlings ( $46 \%$ ) when involved in intra-class crossings, followed by backcrosses (32\%). For P. axillaris as a pollen receiver, a higher success was observed in backcrosses (66\%), with much lower percentages of germinated seeds with the other pollination treatments. Hybridization between these Petunia species was the least effective pollination treatment for both species: on average, only $18 \%$ of all seedlings came from this kind of crosses (22\% for P. exserta mothers; $16 \%$ for P. axillaris plants).

\section{Correlation between floral traits and pollination treatments}

We did not observe correlation either between corolla tube length/seed quantities or between tube length/stigmadorsal anthers distance $(r=-0.14$ and -0.09 , respectively, $p$ $=0.518)$. There was no correlation also between these floral traits and germinability $(r=0.01$ and 0.30 , respectively, $p$ $=0.235)$. Floral traits were also not associated $(r=-0.07 ; p$
$=0.768)$. To check whether these results were not due to variable distribution issues, we calculated Spearman's rank correlations, and no statistical significance was achieved (all $\operatorname{six} p$ values $>0.14$ ).

\section{Discussion}

Herein, we investigated individuals' reproductive compatibility from a contact zone between $P$. exserta and $P$. axillaris through a range of hand pollination tests conducted under controlled and uniform conditions. Our experiments revealed that $P$. exserta, $P$. axillaris, and their interspecific hybrids are self-compatible. Individuals of $P$. exserta and hybrids are also occasionally autogamous. We observed no significant barriers for mates between individuals and between lineages because almost all pollination treatments produced fruits with viable seeds. Seedling's viability is equally low for all phenotypes, but it seems enough to maintain the populations as no differences in the number

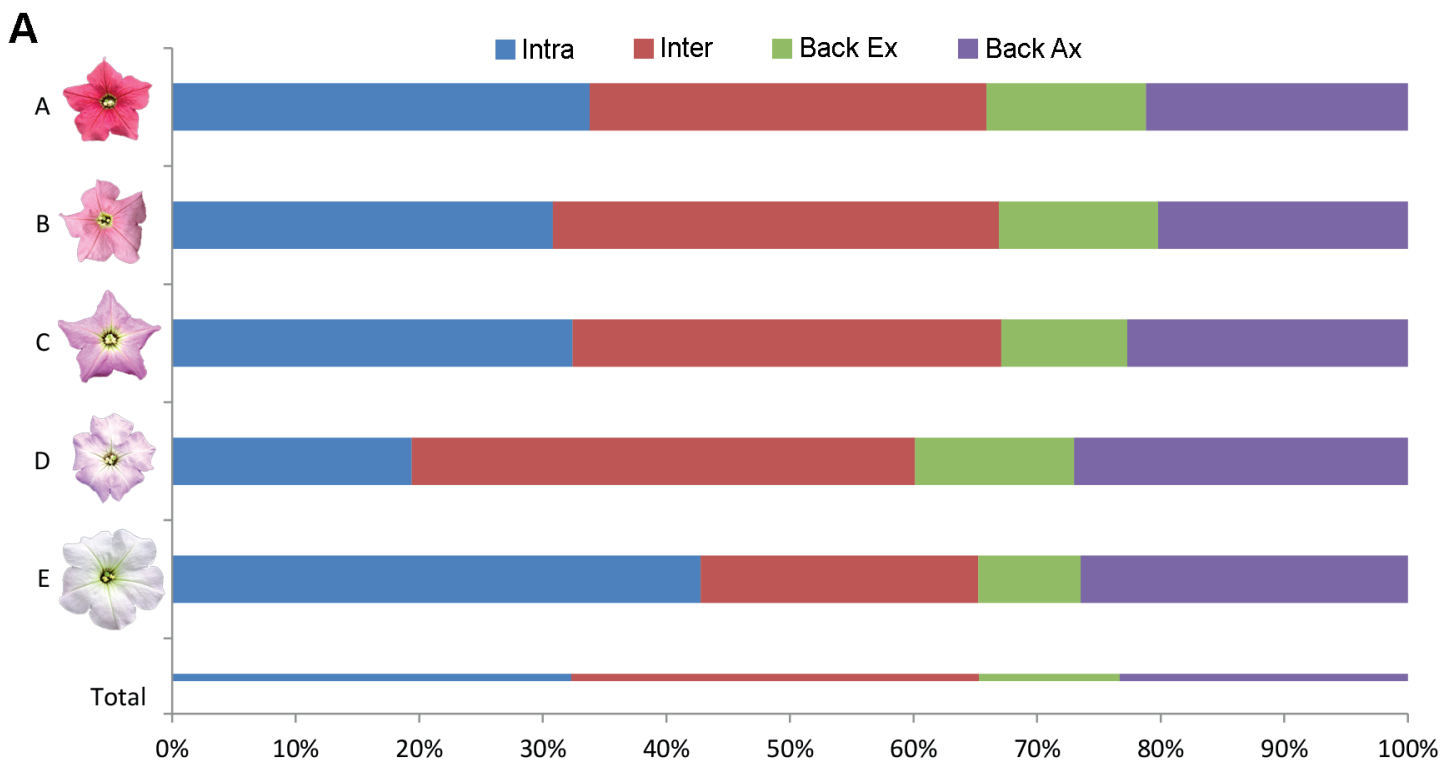

B

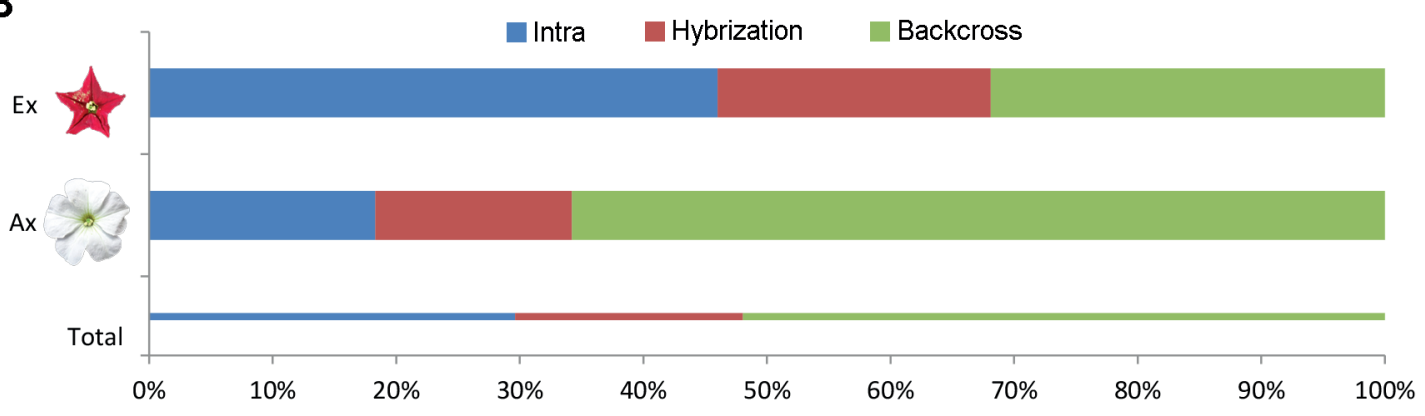

Figure 3. Schematic representation for each pollination treatment contribution on the seed germination as estimated through Pearson's chi-square and considering intermediate coloured $(\mathbf{A})$ and canonical $(\mathbf{B})$ individuals. For individual and significance values, see Tables S5 and S6 in supplementary material. 
of individuals have been observed along time (Schnitzler et al. 2020).

As previously described (Watanabe et al. 2001), we observed higher reproductive success (translated as seed production) in interspecific crosses when $P$. exserta acts as the mother plant. Under controlled crosses and cultivation, $P$. exserta mother plants produced proportionally more viable seedlings (22\%) than P. axillaris (16\%), which evidenced a unilateral interspecific incompatibility that is commonly observed in Solanaceae species (Watanabe et al. 2001) and consists of several mechanisms to restrict pollination between different species (initially proposed by Lewis \& Crowe 1958). Such mechanisms would protect $P$. axillaris species integrity more than $P$. exserta, which can be expected considering the evolutionary history of these two taxa (Turchetto et al. 2019b) as P. exserta has been originated from P. axillaris. In nature, just a few hybrid morphotypes were found outside shelters together with canonical P. axillaris individuals (Turchetto et al. 2019a; b; Schnitzler et al. 2020; Teixeira et al. 2020), which reinforces the idea of a well-established system protecting $P$. axillaris from gene exchanging with a sympatric congener. Moreover, the same gene set that allowed P. exserta divergence and adaptation to a particular environment could restrict hybrids' development outside the shelters (Caballero-Villalobos et al. 2021).

The structure and fate of a population are strongly influenced by the reproductive potential of its individuals (Ghazoul 2005) and shifts in the floral traits of pollinatordependent plants have been implicated in the establishment of reproductive barriers between individuals and lineages (Peakall \& Whitehead 2014; van der Niet et al. 2014) that may put the population's survival at risk. In the contact zone between P. exserta and P. axillaris, we have followed two sites encompassing canonical individuals as well as interspecific hybrids that have several changes in morphology (Teixeira et al. 2020) and genetic profiles (Turchetto et al. 2019b) comprising stable populations, despite being reduced in size (Lorenz-Lemke et al. 2006; Segatto et al. 2014; Turchetto et al. 2015b). Recent analyses based on these sites' genetic composition showed that individuals are mainly $F_{2}$ hybrids or products from backcrosses with canonical individuals of both species across different flowering seasons (Schnitzler et al. 2020). Hybrids were always found inside shelters (Turchetto et al. 2019b; Schnitzler et al. 2020), close to $P$. exserta plants, and $F_{1}$ hybrids were rarely observed. Our current results concerning the compatibility among hybrids and backcrosses support the hypothesis that this contact zone represents a stable population, promoting introgression (Turchetto et al. 2019a; b) and increasing morphological variability (Teixeira et al. 2020) in both $P$. exserta and P. axillaris.

In general, small populations suffer from pollen limitation, which occurs when individuals receive less pollen than necessary to reach their full reproductive success that, if chronic, can lead to the development of selfing strategies (Runquist \& Moeller 2014). Self-fertilization is also usually seen in contact zones between closely related species (Brys et al. 2014), as in P. axillaris (Turchetto et al. 2015a). Furthermore, species with limited dispersal and spatially structured populations may have reduced genetic neighborhood, implying an increase in mating between relatives (Carrillo-Angeles et al. 2011), as observed in $P$. secreta (Rodrigues et al. 2019), another Petunia species from the same geographical distribution and closely related to the P. exserta and P. axillaris (Reck-Kortmann et al. 2014).

Self-fertility increases when $P$. hybrida (Flaschenreim \& Ascher 1980) plants are exposed to reduced light intensity similar to that inside shelters where P. exserta and intermediate coloured individuals are found. An alternative hypothesis is that small populations could experience an absence of pollinators as was already observed in other studies (Vesprini \& Galetto 2000; Amorim et al. 2014). Moreover, in populations with a small number of individuals and few flowers per plant, such as those of the Petunia species, self-pollination may be increased because pollinators tend to visit conspecific flowers less frequently than they do in large populations (Levin 2012).

If, on the one hand, self-pollination increases the reproductive chances of an invasive species or those living under adverse ecological conditions (Levin 2012), inbreeding can increase the expression of deleterious allele combinations that may also contribute to inbreeding depression (Charlesworth \& Willis 2009). However, the magnitude of the endogamic depression effect depends on the mating system and the number of generations under inbreeding (Luijten et al. 2002). Here, we observed that selfing pollination treatments did not significantly reduce the seed viability, which usually seems low in these two Petunia species and their hybrids, suggesting that these mating systems may have stabilized the populations in the contact zone between P. exserta and P. axillaris. Moreover, it was previously suggested that inbreeding keeps the species borders (Segatto et al. 2014; Turchetto et al. 2015a; 2019a). However, species' integrity can also be maintained by postzygotic isolating that limits the fitness of hybrids (Coyne \& Orr 2004). The most limiting barrier for these Petunia species and their hybrids establishment seems to be the environmental differential selection (CaballeroVillalobos et al. 2021) that could prevent the development of $P$. axillaris inside caves and almost totally prevent hybrids growth outside shelters.

In monoecious plants, such as Petunia species, it is useful to distinguish the mating system to understand population permanence and diversity (Charlesworth 2006). Here, we described high self-compatibility levels in three co-occurring lineages that also produce viable seedlings in hand-crosses under controlled conditions. Such potential could, at least in part, explain the population stability as a secondary contact zone between $P$. exserta and $P$. axillaris and the hybrids' occurrence among generations, genetic 


\section{Marcelo C. Teixeira, Caroline Turchetto, Carolina K. Schnitzler, Sidia M. Callegari-Jacques and Loreta B. Freitas}

diversity in those populations (Turchetto et al. 2019b), and introgression-generating morphological diversity (Teixeira et al. 2020).

In both P. exserta and P. axillaris, there is a set of genes with tight genetic linkage that provides a mechanism for rapid switches between their distinct pollination syndromes in response to changes in pollinator availabilities (Hermann et al. 2013) and have molecular mechanisms of colour differences that are related to the pollinator preferences (Hoballah et al. 2007; Sheehan et al. 2016). Moreover, occasional visits of hummingbirds have been reported for P. axillaris populations (Lorenz-Lemke et al. 2006; Gübitz et al. 2009), and flowers of these two species share some scent compounds that can be attractive to bees (Rodrigues et al. 2018b). However, we did not observe Pseudagapostemun sp. collecting pollen from $P$. axillaris, $P$. exserta, or hybrids between them. The hybrids display several pink shades, which are attractive to bees. Such corolla colour shifts are attributed to the loss and regain of just one gene in Petunia species (Esfeld et al. 2018). Thus, the formation and maintenance of hybrid zones between P. exserta and $P$. axillaris can be associated with incomplete discrimination by pollinators and high compatibility levels among hybrids and canonical individuals.

In summary, high self-compatibility and seed viability in these three lineages (canonical individuals of each species and interspecific hybrids) that occur in a contact zone promote the establishment of stable populations and facilitate gene exchange and introgression in these populations. Combined with previous studies on the genetic constitution and morphological characterization, the present results contribute to understanding the Petunia diversification process.

\section{Acknowledgements}

This work was supported by the Conselho Nacional de Desenvolvimento Científico e Tecnológico (CNPq), the Coordenação de Aperfeiçoamento de Pessoal de Nível Superior (CAPES), and the Programa de Pós-graduação em Botânica da Universidade Federal do Rio Grande do Sul (PPGBot-UFRGS). C.T. was supported by PNPD-CAPES/ PPGBM, UFRGS.

\section{References}

Amorim FW, Wyatt GE, Sazima M. 2014. Low abundance of longtongued pollinators leads to pollen limitation in four specialized hawkmoth-pollinated plants in the Atlantic Rain forest, Brazil. Naturwissenschaften 101: 893-905

Ando T, Nomura M, Tsukahara J, et al. 2001. Reproductive isolation in a native population of Petunia sensu Jussieu (Solanaceae). Annals of Botany 88: 403-413.

Ando T, Tsukamoto T, Akiba N, et al. 1998. Differentiation in the degree of self-incompatibility in Petunia axillaris (Solanaceae) occurring in Uruguay. Acta Phytotaxonomica et Geobotanica 49: 37-47.
Ando T. 1996. Distribution of Petunia axillaris (Solanaceae) and its new subspecies in Argentina and Bolivia. Acta Phytotaxonomica et Geobotanica 47: 19-30.

Bigio L, Lebel M, Sapir Y. 2017. Do different measures of maternal fitness affect estimation of natural selection on floral traits? A lesson from Linum pubescens (Linaceae). Journal of Plant Ecology 10: 406-413.

Brys R, Broeck AV, Mergeay J, Jacquemyn H. 2014. The contribution of mating system variation to reproductive isolation in two closely related Centaurium species (Gentianaceae) with a generalized flower morphology. Evolution 68: 1281-1293.

Caballero-Villalobos LM, Silva-Arias GA, Turchetto C, et al. 2021. Neutral and adaptive genomic variation in hybrid zones of two ecologically divergent Petunia species. Botanical Journal of the Linnean Society 196: 100-122.

Carrillo-Angeles IG, Mandujano MC, Golubov J. 2011. Influences of the genetic neighborhood on ramet reproductive success in a clonal desert cactus. Population Ecology 53: 449-458.

Charlesworth D, Willis JH. 2009. The genetics of inbreeding depression. Nature Review Genetics 10: 783-796.

Charlesworth D. 2006. Balancing selection and its effects on sequences in nearby genome regions. PLOS Genetics 2: e2. doi: 10.1371/journal. pgen.0020064

Cheptou PO. 2019. Does the evolutionary of self-fertilization rescue populations or increase the risk of extinction? Annals of Botany 123: 337-345.

Coyne J, Orr HA. 2004. Speciation. Sunderland, Sinauer Associates, Inc. Dell' Olivo A, Kuhlemeier C. 2013. Asymmetric effects of loss and gain of a floral trait on pollinator preference. Evolution 67: 3023-3031.

Ellstrand NC, Meirmans P, Rong J, et al. 2013. Introgression of crop alleles into wild or weedy populations. Annual Review in Ecology, Evolution and Systematics 44: 325-345.

Esfeld K, Berardi AE, Moser M, Bossolini E, Freitas L, Kuhlemeier C. 2018. Pseudogenization and resurrection of a speciation gene. Current Biology 28: 3776-3786.

Etcheverry AV, Alemán CET. 2005. Reproductive biology of Erythrina falcata (Fabaceae: Papilionoideae). Biotropica 37: 54-63.

Flaschenriem DR, Ascher PD. 1980. Winter environment increases selfseed yield in self-incompatible (SI) Petunia hybrida clones. Euphytica 29: 581-584.

Fregonezi JN, Turchetto C, Bonatto SL, Freitas LB. 2013. Biogeographical history and diversification of Petunia and Calibrachoa (Solanaceae) in the Neotropical Pampas grassland. Botanical Journal of the Linnean Society 171: 140-153.

Galetto L, Bernardello L. 1993. Nectar secretion pattern and removal effects in three species of Solanaceae. Canadian Journal of Botany 71: 1394-1398

Ghazoul J. 2005. Pollen and seed dispersal among dispersed plants. Biological Reviews 80: 413-443.

Gübitz T, Hoballah ME, Dell' Olivo A, Kuhlemeier C. 2009. Petunia as a model system for the genetics and evolution of pollination syndromes. In: Gerats T, Strommer J. (eds.) Petunia Evolutionary, Developmental and Physiological Genetics. New York, Springer. p. 29-49.

Hermann K, Klahre U, Moser M, Sheehan H, Mandel T, Kuhlemeier C. 2013. Tight genetic linkage of prezygotic barrier loci creates a multifunctional speciation island in Petunia. Current Biology 23: 873-877.

Hoballah ME, Gubitz T, Stuurman J, et al. 2007. Single gene-mediated shift in pollinator attraction in Petunia. Plant Cell 19: 779-790.

Hopkins R. 2013. Reinforcement in plants. New Phytologist 197: 1095-1103.

Karron JD, Ivey CT, Mitchell RJ, Whitehead MR, Peakall R, Case AL. 2012. New perspectives on the evolution of plant mating systems. Annals of Botany 109: 493-503.

Keller LF, Waller DM. 2002. Inbreeding effects in wild populations. Trends in Ecology and Evolution 17: 230-241.

Knapp S. 2010. On 'various contrivances': pollination, phylogeny and flower form in the Solanaceae. Philosophical Transactions of the Royal Society Biological Sciences 365: 449-460.

Kokubun H, Nakano M, Tsukamoto T, et al. 2006. Distribution of selfcompatible and self-incompatible populations of Petunia axillaris (Solanaceae) outside Uruguay. Journal of Plant Research 119: 419-430. 


\section{Could the reproductive system explain the stability and long-term persistence in a natural hybrid zone of Petunia (Solanaceae)?}

Levin DA. 2012. Mating system shifts on the trailing edge. Annals of Botany 109: 613-620.

Lewis D, Crowe LK. 1958. Unilateral interspecific incompatibility in flowering plants. Heredity 12: 233-256.

Lorenz-Lemke AP, Mäder G, Muschner VC, et al. 2006. Diversity and natural hybridization in a highly endemic species of Petunia (Solanaceae): a molecular and ecological analysis. Molecular Ecology 15: 4487-4497.

Luijten SH, Kéry M, Oostermeijer JGB, den Nijs HJCM. 2002. Demographic consequences of inbreeding and outbreeding in Arnica montana: a field experiment. Journal Ecology 90: 593-603.

Oakley CG, Agren J, Schemske DW. 2015. Heterosis and outbreeding depression in crosses between natural populations of Arabidopsis thaliana. Heredity 115: 73-82.

Peakall R, Whitehead MR. 2014. Floral odor chemistry defines species boundaries and underpins strong reproductive isolation in sexually deceptive orchids. Annals of Botany 113: 341-355.

Reck-Kortmann M, Silva-Arias GA, Segatto ALA, Mäder G, Bonatto SL, Freitas LB. 2014. Multilocus phylogeny reconstruction: new insights into the evolutionary history of the genus Petunia. Molecular Phylogenetics and Evolution 81: 19-28.

Rodrigues DM, Caballero-Villalobos LM, Turchetto C, Jacques RA, Kuhlemeier C, Freitas LB. 2018b. Do we truly understand pollination syndromes in Petunia as much as we suppose? AoB Plants 10: ply057. doi: 10.1093/aobpla/ply057

Rodrigues DM, Turchetto C, Callegari-Jacques SM, Freitas LB. 2018a. Can reproductive system of a rare and narrowly endemic plant species explain its high genetic diversity? Acta Botanica Brasilica 32: 180-187.

Rodrigues DM, Turchetto C, Lima JS, Freitas LB. 2019. Diverse yet endangered: pollen dispersal and mating system reveal inbreeding in a narrow endemic plant. Plant Ecology \& Diversity 12: 169-180.

Runquist RDB, Moeller DA. 2014. Floral and mating system divergence in secondary sympatry: testing an alternative hypothesis to reinforcement in Clarkia. Annals of Botany 113: 223-235.

Schnitzler CK, Turchetto C, Teixeira MC, Freitas LB. 2020. What could be the fate of secondary contact zones between closely related plant species? Genetics and Molecular Biology 43: e20190271. doi: 10.1590/1678-4685-GMB-2019-0271

Segatto ALA, Cazé ALR, Turchetto C, et al. 2014. Nuclear and plastid markers reveal the persistence of genetic identity: a new perspective on the evolutionary history of Petunia exserta. Molecular Phylogenetics and Evolution 70: 504-512.

Sheehan H, Moser M, Klahre U, et al. 2016. MYB-FL controls gain and loss of floral UV absorbance, a key trait affecting pollinator preference and reproductive isolation. Nature Genetics 48: 159-166.

Soltis PS, Soltis DE. 2009. The role of hybridization in plant speciation. Annual Review in Plant Biology 60: 561-588.

Stehmann JR, Lorenz-Lemke AP, Freitas LB, Semir J. 2009. The genus Petunia. In: Gerats T, Strommer J. (eds.) Petunia Evolutionary, Developmental and Physiological Genetics. New York, Springer. p. 1-28.
Teixeira MC, Turchetto C, Hartke S, Schnitzler CK, Freitas LB. 2019. Morphological and genetic perspectives of hybridization in two contact zones of closely related species of Petunia (Solanaceae) in southern Brazil. Acta Botanica Brasilica 33: 734-740.

Teixeira MC, Turchetto C, Maestri R, Freitas LB. 2020. Morphological characterization of sympatric and allopatric populations of Petunia axillaris and P. exserta (Solanaceae). Botanical Journal of the Linnean Society 192: 550-567.

Todesco M, Pascua MA, Owens GL, et al. 2016. Hybridization and extinction. Evolutionary Applications 9: 892-908.

Turchetto C, Fagundes NJR, Segatto ALA, et al. 2014a. Diversification in the South American Pampas: the genetic and morphological variation of the widespread Petunia axillaris complex (Solanaceae). Molecular Ecology 23: 374-389.

Turchetto C, Lima JS, Rodrigues DM, Bonatto SL, Freitas LB. 2015a. Pollen dispersal and breeding structure in a hawkmoth-pollinated Pampa grasslands species Petunia axillaris (Solanaceae). Annals of Botany 115: 939-948.

Turchetto C, Schnitzler CK, Freitas LB. 2019a. Species boundary and extensive hybridization and introgression in Petunia. Acta Botanica Brasilica 33: 724-733.

Turchetto C, Segatto ALA, Beduschi J, Bonatto SL, Freitas LB. 2015b. Genetic differentiation and hybrid identification using microsatellite markers in closely related wild species. AoB Plants 7: plv084. doi: 10.1093/aobpla/plv084

Turchetto C, Segatto ALA, Silva-Arias GA, et al. 2019b. Contact zones and their consequences: hybridization between two ecologically isolated wild Petunia species. Botanical Journal of the Linnean Society 190: 421-435.

Turchetto C, Segatto ALA, Telles MPC, Diniz-Filho JAF, Freitas LB. 2014b. Infraspecific classification reflects genetic differentiation in the widespread Petunia axillaris complex: a comparison among morphological, ecological, and genetic patterns of geographic variation. Perspectives in Plant Ecology, Evolution and Systematics 16: 75-82.

van der Niet T, Pirie MD, Shuttleworth A, Johnson SD, Midgley JJ. 2014. Do pollinator distributions underlie the evolution of pollination ecotypes in the Cape shrub Erica plukenetii? Annals of Botany 113: 301-315.

Venail J, Dell' Olivo A, Kuhlemeier C. 2010. Speciation genes in the genus Petunia. Philosophical Transactions of the Royal Society B 365: 461-468.

Vesprini JL, Galetto L. 2000. The reproductive biology of Jaborosa integrifolia (Solanaceae): Why its fruits are so rare? Plant Systematics and Evolution 225: 15-28.

Vilà M, Weber E, Antonio CM. 2000. Conservation implications of invasion by plant hybridization. Biological Invasions 2: 207-217.

Watanabe H, Ando T, Tsukamoto T, Hashimoto G, Marchesi E. 2001. Crosscompatibility of Petunia exserta with other Petunia taxa. Journal of the Japanese Society for Horticultural Science 70: 33-40.

Wubs ERJ, Groot GA, During HJ, Vogel JC, Grundmann PB, Schneider H. 2010. Mixed mating system in the fern Asplenium scolopendrium: implications for colonization potential. Annals of Botany 106: 583-590. 